\title{
2-Alkyl-2-methyl- and 2-Alkyl-2,4-dimethyl-1,3-dioxanes
}

\author{
IV. Hydrolytic Decomposition of 2-Alkyl-2-methyl-1,3-dioxanes. The \\ Dependence of the Hydrolysis Rates on the Conformer Ratios
}

\author{
KALEVI PIHLAJA and KARI-JAAKKO TEINONEN \\ Department of Chemistry, University of Turku, Turku 2, Finland
}

\begin{abstract}
Second-order rate coefficients of the acid-catalyzed hydrolysis of 2,2-dimethyl-, 2,2-diethyl-, 2-ethyl-2-methyl-, 2-propyl-2-methyl-, 2-isopropyl-2-methyl-, 2-butyl-2-methyl-, 2-s-butyl-2-methyl-, and 2-t-butyl-2-methyl-1,3-dioxanes in dilute perchloric acid solutions have been determined. The individual rates of both conformers were evaluated for the compounds with different alkyl substituents. A similar dependence of the rate coefficients on polar and steric effects prevails in the case of the studied compounds as found for 2-alkyl2,4-dimethyl-1,3-dioxanes.
\end{abstract}

It has been shown earlier that 2-alkyl-2,4-dimethyl-1,3-dioxanes are
hydrolyzed according to an A-1 mechanism.,2 An NMR investigation
revealed that the conformer ratios of 2-alkyl-2-methyl-1,3-dioxanes ${ }^{3}$ are in
accordance with equilibration data for several stereoisomeric 2 -alkyl-2,4-
dimethyl-1,3-dioxanes. ${ }^{4}$ A study of the hydrolytic decomposition of 2 -alkyl-
2,4-dimethyl-1,3-dioxanes showed that separate Taft-Hammett plots are
obtained for the trans and the cis series. ${ }^{2}$ The aims of this study were to measure
the hydrolysis rates, to determine the values of the free energy of activation
for the individual conformers and to determine the dependence of the rates
on polar and steric factors.

\section{EXPERIMENTAL}

The studied compounds were prepared earlier. ${ }^{3}$ The kinetic measurements were made spectrophotometrically as described previously. ${ }^{2}$ The values of the hydrolysis rates were determined at at least three temperatures for each compound (Table 1).

\section{RESULTS AND DISCUSSION}

The hydrolysis rates of the individual conformers of 2-alkyl-2-methyl-1,3dioxanes can be estimated with the aid of the equations:

Acta Chem. Scand. 25 (1971) No. 1 


$$
\begin{aligned}
& k_{\mathrm{E}} / k_{\mathrm{A}}=k \text { (trans-2,4-dimethyl-2-alkyl-1,3-dioxane }) / k(\text { cis-2,4-dimethyl- } \\
&\text { 2-alkyl-1,3-dioxane })
\end{aligned}
$$

where $k_{\mathrm{E}}$ is the rate of hydrolysis of the conformer with an equatorial alkyl group, $k_{\mathrm{A}}$ that of the conformer with an axial alkyl group, and $x_{\mathrm{E}}$ the mole fraction of the conformer with an equatorial alkyl group in the conformer mixture.

The second-order rate coefficients of the acid-catalyzed hydrolysis of cisand trans-2,4-dimethyl-2-alkyl-1,3-dioxanes were measured or estimated in a previous paper ${ }^{2}$ (Table 1). The mole fractions of the conformers of 2-alkyl-2methyl-1,3-dioxanes were determined from NMR shifts of the methyl protons by Pihlaja and Äyräs.3

The values of the rate coefficients of the acid-catalyzed hydrolysis of the $2 e-\mathrm{R}, 2 a-\mathrm{Me}$ and $2 a-\mathrm{R}, 2 e-\mathrm{Me}$ forms of 2-alkyl-2-methyl-1,3-dioxanes estimated from eqns. (1) and (2) are presented in Table 3. The rates of hydrolysis of the conformers with axial alkyl groups differ only slightly from the rate of hydrolysis of "frozen" 2,2-dimethyl-1,3-dioxane. The rate of hydrolysis of $2 a$ isobutyl-2e-methyl-1,3-dioxane is, however, clearly higher, in agreement with

\begin{tabular}{|c|c|c|c|c|c|c|c|}
\hline 1,3-Dioxanes & $12.1^{\circ} \mathrm{C}$ & $20.0^{\circ} \mathrm{C}$ & $25.0^{\circ} \mathrm{C}$ & $\begin{array}{r}k_{\mathrm{a}}, \\
30.0^{\circ} \mathrm{C}\end{array}$ & $\begin{array}{l}{ }^{-1} \mathrm{~B}^{-1} \\
35.0^{\circ} \mathrm{C}\end{array}$ & $40.0^{\circ} \mathrm{C}$ & $44.4^{\circ} \mathrm{C}$ \\
\hline 2,2-diMe & & & 9.40 & & 22.3 & & 46.3 \\
\hline 2,2-diEt & & & 18.5 & & 46.5 & & 106.7 \\
\hline 2-Me-2-Et & & & 15.0 & & 40.8 & & 91.4 \\
\hline $2-\mathrm{Me}-2-\mathrm{Pr}$ & & & 14.15 & & 34.7 & & 80.75 \\
\hline $2-\mathrm{Me} \cdot 2 \cdot \mathrm{Bu}$ & & & 19.25 & & 42.45 & & 85.25 \\
\hline 2-Me-2-i.Pr & & & 24.2 & & 55.0 & & 125.8 \\
\hline 2-Me-2-i-Bu & & & 60.5 & 89.75 & 131.8 & & \\
\hline 2-Me-2-s-Bu & & & 32.8 & 49.8 & & 104.65 & 154.1 \\
\hline 2-Me-2-t-Bu & 60.4 & 118.2 & 172.5 & & & & \\
\hline 2,4-diMe-2-i-Bu $(c i s)^{1}$ & & & 15.9 & & & & \\
\hline 2,4-diMe-2-i-Bu $(\operatorname{tran} s)^{1}$ & & & 40.9 & & & & \\
\hline 2,4-diMe-2-i-Pr $(c i s)^{1}$ & & & 4.26 & & & & \\
\hline $2,4-d i M e-2-i-\operatorname{Pr}(\operatorname{trans})^{1}$ & & & $\mathbf{3 4 . 0}$ & & & & \\
\hline 2,4-diMe-2-8-Bu $(c i s)^{1}$ & & & 5.1 & & & & \\
\hline 2,4-diMe-2-s-Bu $(\operatorname{tran} s)^{1}$ & & & 51.1 & & & & \\
\hline 2,4-diMe-2-t-Bu $(c i s)^{1}$ & & & $5.35^{a}$ & & & & \\
\hline 2,4-diMe-2-t-Bu $(\operatorname{tran} s)^{1}$ & & & 177 & & & & \\
\hline 2,4-diMe-2-Et $(c i s)^{1}$ & & & 4.64 & & & & \\
\hline 2,4-diMe-2-Et $(\operatorname{tran} s)^{1}$ & & & 14.0 & & & & \\
\hline 2,4-diMe-2.Pr $(c i s)^{1}$ & & & 6.0 & & & & \\
\hline 2,4-diMe-2-Pr $(\operatorname{trans})^{1}$ & & & 20.8 & & & & \\
\hline 2,4-diMe-2-Bu $(c i s)^{1}$ & & & 7.1 & & & & \\
\hline 2,4-diMe-2-Bu $(\operatorname{tran} s)^{1}$ & & & 29.4 & & & & \\
\hline
\end{tabular}

Table 1. Second-order rate coefficients of the acid-catalyzed hydrolysis of 2-alkyl-2-methyland 2-alkyl-2,4-dimethyl-1,3-dioxanes at different temperatures.

${ }^{a}$ For the hypothetical chair form. 


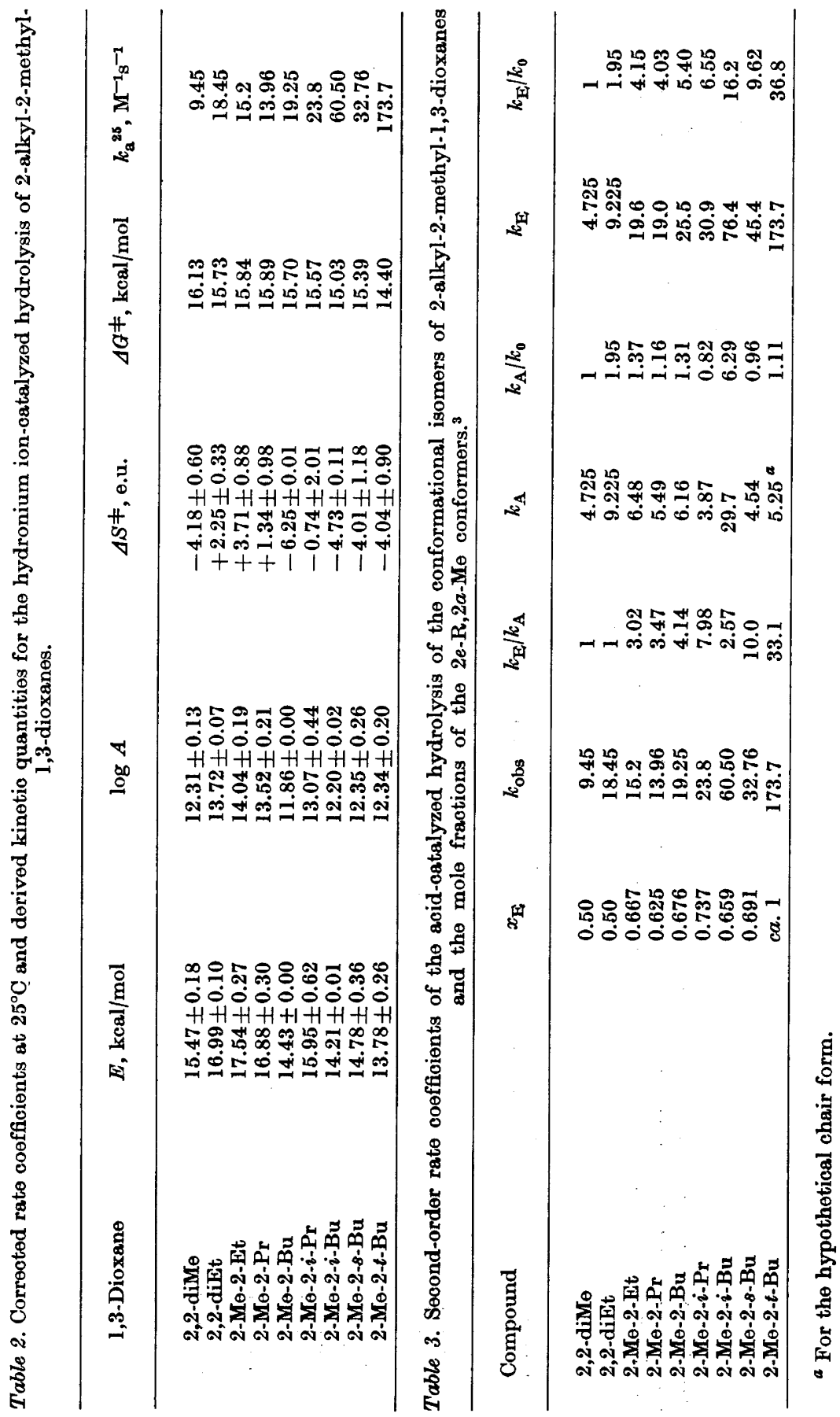

Acta Chem. Scand. 25 (1971) No. 1 


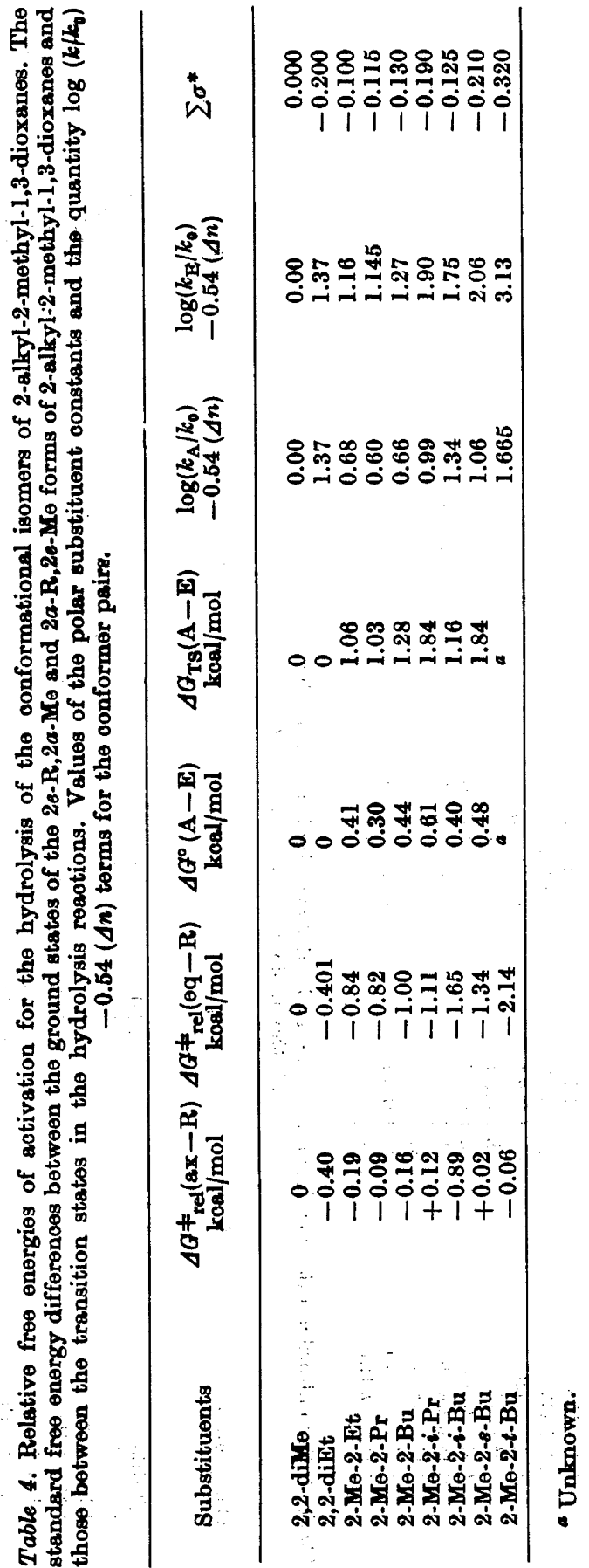

Acta Chem. Scaind. 25 (1971) No. 1 
the strong interactions between the methyl groups of the isobutyl group and the equatorial 2-methyl substituent or the ring oxygen atoms..$^{1,3}$ The rates of 2e-alkyl-2a-methyl-1,3-dioxanes increase appreciably in the order $\mathrm{Me}<\mathrm{Et} \simeq$ $\operatorname{Pr}<\mathrm{Bu}<i$ - $\operatorname{Pr}<s-\mathrm{Bu}<t-\mathrm{Bu}$ in accordance with the values of the polar substituent constants. Again, the isobutyl derivative is more reactive owing to additional interactions, which are similar to those in the other conformer, i.e. the ground state energies of 2-isobutyl-2-methyl-1,3-dioxanes are somewhat higher than those of the other compounds.

The free energies of activation of the conformational isomers of 2-alkyl-2methyl-1,3-dioxanes and "frozen" 2,2-dimethyl-1,3-dioxane (Table 2; 16.13+ $R T \ln 2 \mathrm{kcal} / \mathrm{mol}$ ) are presented in Table 3 together with the standard free energy differences between the ground states of the $2 a-\mathrm{R}, 2 e-\mathrm{Me}$ and $2 e-\mathrm{R}$, $2 a-\mathrm{Me}$ forms. These values show that the steric requirements of the axial alkyl groups increase the free energy of the transition state clearly more than those of the equatorial alkyl groups (Fig. 1). Branching at the $\alpha$-position of the alkyl chain decreases appreciably the stability of the transition state of the $2 a-\mathrm{R}, 2 e-\mathrm{Me}$ forms, whereas chain length has only a minor effect.

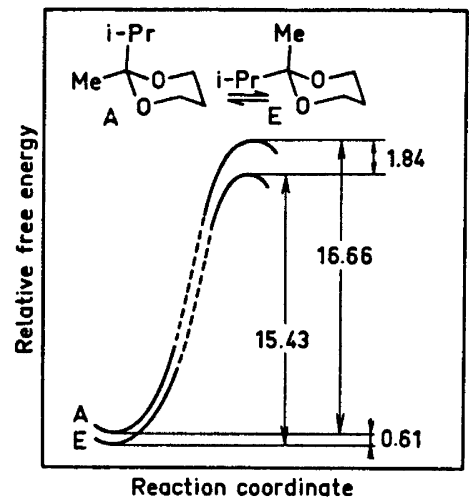

Fig. 1. The free energy profiles for the hydrolytic decomposition of the conformational isomers of 2-isopropyl-2methyl-1,3-dioxane.

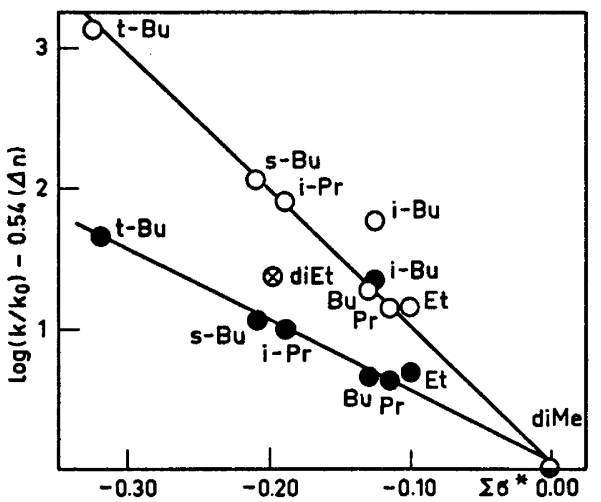

Fig. 2. The Taft-Hammett plots for the hydrolysis of the conformational isomers of 2-alkyl-2-methyl-1,3-dioxane. $O$, equatorial alkyl groups; , axial alkyl groups; $\oplus, 2,2$-diethyl-1,3-dioxane.

The dependence of the hydrolysis rates of the conformational isomers of 2-alkyl-2-methyl-1,3-dioxanes on polar factors is presented by Taft-Hammett plots (3) in Fig. 2:2,5

$$
\log \left(k / k_{0}\right)-(\Delta n) \times 0.54=\sum \sigma^{*} \varrho^{*}+\mathrm{b}
$$

where $k$ is the rate coefficient of the conformer in question, $k_{0}$ that of "frozen" 2,2-dimethyl-1,3-dioxane, and $\Delta n$ an integer which is the difference in the numbers of $\alpha$-hydrogen atoms in the substituents of the reference acetal and

Acta Chem. Scand. 25 (1971) No. 1 
the compound in question. Good linear correlations are found for both series of conformers (Fig. 2), excluding again ${ }^{1}$ the isobutyl derivatives, owing to the severe crowding of the substituents which increases the free energies of their ground states.

The derived Taft-Hammett equations

2a-R-series: $(-5.041 \pm 0.278) \sigma^{*}+(0.041 \pm 0.050)$

2e-R-series: $(-9.645 \pm 0.289) \sigma^{*}+(0.056 \pm 0.052)$

are in close agreement with those derived earlier for cis-and trans-2,4-dimethyl2-alkyl-1,3-dioxanes:

cis series: $(-5.044 \pm 0.275) \sigma^{*}-(0.014 \pm 0.034)$

trans series: $(-9.782 \pm 0.236) \sigma^{*}-(0.012 \pm 0.029)$

This agreement confirms the value of NMR spectroscopy as a method for determining the relative amounts of conformers.

\section{REFERENCES}

1. Pihlaja, K. Ann. Univ. Turkuensis Ser. A I (1967) No. 114, Thesis.

2. Pihlaja, K. and Teinonen, K. J. Suomen Kemistilehti B 43 (1970) 206. (Part III.)

3. Pihlaja, K. and Āyräs, P. Suomen Kemistilehti B 43 (1970) 171. (Part I.)

4. Pihlaja, K. and Tenhosaari, A. Suomen Kemistilehti B 43 (1970) 175. (Part II.)

5. Kreevoy, M. M. and Taft, Jr., R. W. J. Am. Chem. Soc. 77 (1955) 5590.

Received June 5, 1970. 